\title{
Downregulation of microRNA-204 increases the expression of matrix metallopeptidase 9 in pediatric patients with pulpitis and Helicobacter pylori infection in the stomach
}

\author{
SHU ZHOU and JI XU \\ Dental Department, Children's Hospital of Nanjing Medical University, Nanjing, Jiangsu 210008, P.R. China
}

Received April 15, 2017; Accepted March 26, 2019

DOI: $10.3892 / \mathrm{etm} .2019 .7528$

\begin{abstract}
The present study examined the expression of microRNA (miRNA or miR)-204 in pulp tissues, blood and saliva from pediatric patients with pulpitis and an underlying Helicobacter pylori (Hp) infection in the stomach, and the mechanism of the associated regulation by miR-204 was assessed. A total of 26 children with pulpitis who received tooth extraction at the Children's Hospital of Nanjing Medical University (Nanjing, China) between December 2014 and August 2016 were diagnosed with Hp infection in the stomach and included in the present study ( $\mathrm{HP}^{+}$group); furthermore, 19 children with pulpitis but without $\mathrm{Hp}$ infection in the stomach were enrolled as a control (HP $\mathrm{HP}^{-}$group). Pulp tissues, blood (serum) and saliva samples were collected from all subjects. Reverse-transcription quantitative polymerase chain reaction was used to determine the expression of miR-204 and matrix metalloproteinase 9 (MMP9) mRNA. Western blot analysis was performed to determine MMP9 protein expression in pulp tissues, while ELISA was performed to measure the contents of MMP9 in serum and saliva. A dual luciferase reporter assay was used to identify the direct interaction between miR-204 and its target protein. The results indicated that Hp infection in the stomach was associated with an upregulation of MMP9 mRNA and protein in pulp tissues, serum and saliva from children with pulpitis. Furthermore, the levels of miR-204 in pulp tissues, serum and saliva from children with pulpitis and $\mathrm{Hp}$ infection in the stomach were significantly reduced. miR-204 was confirmed to regulate the expression of MMP9 by directly binding with the 3'-untranslated region of MMP9 mRNA. The present study demonstrated that MMP9 expression in pulp tissues, blood and saliva from children with pulpitis and Hp infection in the stomach was upregulated, while miR-204 expression was downregulated. miR-204 may
\end{abstract}

Correspondence to: Dr Ji Xu, Dental Department, Children's Hospital of Nanjing Medical University, 72 Guangzhou Road, Nanjing, Jiangsu 210008, P.R. China

E-mail: xuji19840303@163.com

Key words: miRNA-204, Helicobacter pylori, pulpitis, matrix metallopeptidase 9 affect inflammatory processes and other oral diseases in children with pulpitis and Hp infection via MMP9, and may be a potential marker for the detection of $\mathrm{Hp}$ infection in children with pulpitis.

\section{Introduction}

Helicobacter pylori $(\mathrm{Hp})$ is a globally transmitted pathogen that has an infection rate of $>90 \%$ in developing countries (1). It is an important pathogenic factor of chronic gastritis and gastroduodenal ulcers, and is closely associated with gastric cancer or gastric mucosa-associated malignant lymphoma $(2,3)$. Studies on the infection source and transmission route of $\mathrm{Hp}$ are becoming more and more important.

The oral cavity is an ideal settling environment for $\mathrm{Hp}$ as a facultative anaerobe (4). Hp infection in the stomach is likely to cause oral diseases. As children tend to have a high-sugar diet while lacking sufficient knowledge to protect their teeth, they are easily affected by pulpitis. The degradation of matrix proteins in pulpitis relies on numerous different endogenous proteases, and proteolytic enzymes are essential for the degradation of extracellular matrix. According to their target molecules, proteolytic enzymes may be divided into three types: Serine proteinases, cysteine proteinases and matrix metalloproteinases (MMPs) (5). The role of MMPs in pulpitis has attracted increasing attention in recent years. It was demonstrated that the activation and expression of MMPs are involved in the inflammatory process associated with pulpitis $(6,7)$. Upregulation of MMP9, a member of the MMP family, is also observed in certain mucosal lesions that are closely associated with Hp infection. However, it has remained elusive whether in pulpitis, the levels of MMP9 are affected by the presence of Hp infection in the stomach. In addition, upstream factors that regulate MMPs also remain to be explored.

MicroRNAs (miRNA or miRs) are a class of non-coding RNA molecules of 18-22 nucleotides in length, which regulate the expression of their target proteins at the mRNA level (8). Altered expression of various miRNAs and proteins in patients with hypertension suggests that miRNAs have important roles in the regulation of proteins that are associated with cardiovascular diseases (9-12). In the present study, miRNA molecules associated with MMP9 were screened using bioinformatics, and the association between miR-204 and MMP9 
was identified. The expression of MMP9 was then assessed in pediatric patients with pulpitis and Hp infection in the stomach, and the association between MMP9 and miR-204 in this context was investigated.

\section{Materials and methods}

Patients. A total of 26 pediatric patients with pulpitis who received tooth extraction at the Children's Hospital of Nanjing Medical University (Nanjing, China) between December 2014 and August 2016 were also diagnosed with $\mathrm{Hp}$ infection in the stomach and therefore included in the present study (HP ${ }^{+}$group). Furthermore, 19 contemporaneous pediatric patients with pulpitis but without stomach infection of $\mathrm{Hp}$ were enrolled as a control (HP' group). Pulp tissues, blood (serum) and saliva were collected from all subjects. All three types of samples were tested using the same protocol. The $\mathrm{HP}^{+}$group comprised 16 males and 10 females (age range, 8-12 years; median age, 9.6 years) and the HP' group comprised 11 males and 8 females (age range, 7-12 years; median age, 9.2 years). None of the patients had previously taken any non-steroidal drugs, proton pump inhibitors, antibiotics or bismuth within two weeks prior to examination. All procedures were approved by the Ethics Committee of Nanjing Medical University (Nanjing, China). Written informed consent was obtained from parents or guardians of all pediatric patients.

Reverse-transcription quantitative polymerase chain reaction (RT-qPCR). Pulp tissues $(100 \mathrm{mg})$ were ground into powder in liquid nitrogen and mixed with $1 \mathrm{ml}$ TRIzol (Thermo Fisher Scientific, Inc., Waltham, MA, USA) for lysis. Total RNA was extracted using the phenol chloroform method. The purity of the RNA was determined by the absorbance at $260 \mathrm{vs} .280 \mathrm{~nm}$ using ultraviolet spectrophotometry (Nanodrop ND2000; Thermo Fisher Scientific, Inc.). Total RNA $(1 \mu \mathrm{g})$ was reverse transcribed into cDNA using the TIANScript II cDNA first strand synthesis kit (cat. no. KR107; Tiangen, Beijing, China) and stored at $-20^{\circ} \mathrm{C}$. The PCR reaction $(25 \mu \mathrm{l})$ was composed of $12.5 \mu \mathrm{l}$ SuperReal PreMix (SYBR-Green; cat. no. FP204; Tiangen), $0.5 \mu 1$ foward primer, $0.5 \mu \mathrm{l}$ reverese primer, $10.5 \mu \mathrm{l}$ sterile water and $1 \mu \mathrm{l}$ cDNA. The following primer pairs were used: MMP9 forward, 5'-GCTGGCAGAGGAATACCTGTAC-3' and reverse, 5'-CAG GGACAGTTGCTTCTGGA-3'; $\beta$-actin forward, 5'-CTGGAA CGGTGAAGGTGACA-3' and reverse, 5'-AAGGGACTTCCT GTAACAACGCA-3'. The reaction was performed in an iQ5 real-time PCR system (Bio-Rad Laboratories, Inc., Hercules, CA, USA) using the following thermocycling conditions: Initial denaturation at $95^{\circ} \mathrm{C}$ for $2 \mathrm{~min} ; 40$ cycles of $95^{\circ} \mathrm{C}$ for $15 \mathrm{sec}$, $60^{\circ} \mathrm{C}$ for $30 \mathrm{sec}$ and $72^{\circ} \mathrm{C}$ for $60 \mathrm{sec}$. The relative expression of MMP9 mRNA was quantified using the $2^{-\Delta \Delta \mathrm{Cq}}$ method and normalized to the internal reference $\beta$-actin (13). Each sample was tested in triplicate.

To assess the expression of miR-204, miRNA was isolated using an miRcute miRNA separation kit (cat. no. FP401-02; Tiangen), and cDNA was synthesized using a miRcute miRNA cDNA first strand synthesis kit (cat. no. KR201; Tiangen). The level of miR-204 was determined using a miRcute miRNA qPCR detection kit (cat. no. FP401; Tiangen). The following primer pairs were used: miR-204 forward, 5'-ACACTC CAGCTGGGTTCCCTTTGTCATCCTAT-3' and reverse,
5'-CTCAACTGGTGTCGTGGA-3'; U6 forward, 5'-CTCGCT TCGGCAGCACA-3' and reverse, 5'-AACGCTTCACGAATT TGCGT-3'. The reaction was performed in an iQ5 real-time PCR system using the following thermocycling conditions: Initial denaturation at $95^{\circ} \mathrm{C}$ for $5 \mathrm{~min} ; 40$ cycles of $95^{\circ} \mathrm{C}$ for $15 \mathrm{sec}, 62^{\circ} \mathrm{C}$ for $15 \mathrm{sec}$ and $72^{\circ} \mathrm{C}$ for $32 \mathrm{sec}$. The relative expression of miR-204 was quantified using the $2^{-\Delta \Delta \mathrm{Cq}}$ method and normalized to the internal reference U6. Each sample was tested in triplicate.

Western blot analysis. All types of samples were mixed with $100 \mu 1$ precooled radioimmunoprecipitation assay lysis buffer containing $1 \mathrm{mM}$ phenylmethylsulfonyl fluoride for lysis of $15 \mathrm{~min}$ at $4^{\circ} \mathrm{C}$. The mixture was then centrifuged at $12,000 \mathrm{x} \mathrm{g}$ for $5 \mathrm{~min}$ at $4^{\circ} \mathrm{C}$. The supernatant was used to determine the protein concentration by using a bicinchoninic acid protein concentration determination kit (cat. no. RTP7102; Real-Times Biotechnology Co., Ltd., Beijing, China). Protein samples were then mixed with SDS loading buffer prior to denaturation in a boiling water bath for $5 \mathrm{~min}$. Subsequently, the samples $(20 \mu \mathrm{g})$ were separated via SDS-PAGE on a $10 \%$ gel. The separated proteins were transferred onto polyvinylidene difluoride membranes on ice (100 V, $2 \mathrm{~h}$ ) and blocked with 5\% skimmed milk at room temperature for $1 \mathrm{~h}$. The membranes were then incubated with rabbit anti-human MMP9 polyclonal primary antibody (1:1,000 dilution; cat. no. ab38898; Abcam, Cambridge, UK) and rabbit anti-human $\beta$-actin primary antibody (1:5,000 dilution; cat. no. ab6276; Abcam) at $4^{\circ} \mathrm{C}$ overnight. After extensive washing with PBS containing Tween 20 (PBST) 3 times for $15 \mathrm{~min}$ each, the membranes were incubated with horseradish peroxidase-conjugated goat anti-rabbit polyclonal secondary antibody (1:3,000 dilution; cat. no. ab6721; Abcam) for $1 \mathrm{~h}$ at room temperature prior to washing with PBST 3 times of $15 \mathrm{~min}$ each. Protein bands were visualized using an enhanced chemiluminescence detection kit (cat. no. ab65623; Abcam) and protein expression was quantified using Image lab v3.0 software (Bio-Rad Laboratories, Inc.) with $\beta$-actin as the loading control.

ELISA. Blood samples were centrifuged at $1,000 \mathrm{x} \mathrm{g}$ for $10 \mathrm{~min}$ to obtain serum. Serum and saliva samples were tested using an MMP9 ELISA kit (cat. no. 2219; BLKW Biotechnology, Beijing, China). In microplates, standards (50 $\mu \mathrm{l})$ and samples (10 $\mu \mathrm{l}$ sample liquid and $40 \mu \mathrm{l}$ diluent) were added into predefined wells. In the wells for standards and samples, horseradish peroxidase-labelled conjugates $(100 \mu \mathrm{l})$ were added prior to sealing the plates for incubation at $37^{\circ} \mathrm{C}$ for $1 \mathrm{~h}$. After washing the plates for 5 times, substrates A $(50 \mu \mathrm{l})$ and B $(50 \mu \mathrm{l})$ were added into each well. After incubation at $37^{\circ} \mathrm{C}$ for $15 \mathrm{~min}$, stop solution $(50 \mu \mathrm{l})$ was added into each well, and the absorbance of each well was measured at $450 \mathrm{~nm}$ within $15 \mathrm{~min}$.

Dual luciferase reporter assay. Bioinformatics prediction is a powerful tool for the study of the functions of miRNAs. To understand the regulatory mechanism of MMP9, miRanda (www.microrna.org/microrna/home.do), TargetScan (www.targetscan.org), PiTa (genie.weizmann. ac.il/pubs/mir07/mir07_data.html), RNAhybrid (bibiserv. techfak.uni-bielefeld.de/rnahybrid) and PICTA (pictar. mdc-berlin.de) were used to predict miRNA molecules that 
may regulate MMP9, and miR-204 was identified as a potential regulator of MMP9 (Fig. 1). According to bioinformatics analysis, wild-type (WT) and mutant 3'-untranslated region (UTR) of the MMP9 mRNA containing the seed regions of miR-204 were chemically synthesized in vitro (14) and cloned into the pMIR-REPORT luciferase reporter plasmid (cat. no. AM5795; Ambion, Thermo Fisher Scientific, Inc.) between the Spe-1 and HindIII restriction sites. 293T cells were cultured in RPMI-1640 medium (cat. no. SH30809.01; Thermo Fisher Scientific, Inc.) supplemented with $10 \%$ fetal bovine serum (cat. no. SH30396.03; Thermo Fisher Scientific, Inc.) at $37^{\circ} \mathrm{C}$ in a $5 \% \mathrm{CO}_{2}$-humidified incubator. $293 \mathrm{~T}$ cells were co-transfected with plasmids $(0.8 \mu \mathrm{g})$ containing the WT or mutant sequences from the 3'-UTR of MMP9 mRNA and agomiR-204 (100 nM; Sangon Biotech, Shanghai, China) using Lipofectamine ${ }^{\circledR} 2000$ (Thermo Fisher Scientific, Inc.). 293T cells in the negative control (NC) group were transfected with agomiR-204 and empty pMIR-REPORT plasmid. Following 24-h incubation, cells were lysed and luciferase activities were measured using the Dual-Luciferase Reporter Assay system (Promega Corporation, Madison, WI, USA), according to the manufacturer's protocol. The luciferase activity was detected using a GloMax 20/20 luminometer (Promega Corporation). Firefly luciferase activity for each group of cells was normalized to Renilla luciferase activity as an internal reference.

Statistical analysis. The results were analyzed using SPSS 18.0 statistical software (SPSS, Inc., Chicago, IL, USA). Values are expressed as the mean \pm standard deviation. Data was analyzed using one-way analysis of variance followed by a post hoc test. In case of homogeneity of variance, the least significant difference and Student-Newman-Keuls methods were used; in the case of heterogeneity of variance, Tamhane's T2 or Dunnett's T3 method was used. $\mathrm{P}<0.05$ was considered to indicate a statistically significant difference.

\section{Results}

Upregulation of MMP9 mRNA in pulp tissues, serum and saliva from pediatric patients with pulpitis may be associated with Hp infection in the stomach. To determine the expression of MMP9 mRNA, RT-qPCR was performed. The results indicated that the levels of MMP9 mRNA in pulp tissues, serum and saliva from the pulpitis patients with $\mathrm{Hp}$ infection in the stomach was significantly higher than that in those without Hp infection $(\mathrm{P}<0.05$; Fig. 2A-C). This result suggested that upregulation of MMP9 mRNA in pulp tissues, serum and saliva from pediatric pulpitis patients may be associated with Hp infection in the stomach.

Increased protein expression of MMP9 in pulpitis pulp tissues is associated with stomach infection of $\mathrm{Hp}$. To determine the protein expression of MMP9 in pulp tissues, western blot analysis was employed. The results indicated that the protein levels of MMP9 in pulp tissues from pulpitis patients with Hp infection in the stomach were significantly elevated compared with those from pulpitis patients without Hp infection $(\mathrm{P}<0.05$; Fig. 3). This result indicated that increased expression of MMP9 protein in pulp tissues from pediatric pulpitis patients may be associated with stomach infection of $\mathrm{Hp}$.

\section{3' uccguauCCUACUGUUUCCCUu 5' hsa-miR-204}

\section{I IIIIIII \\ 91:5' cuguucuGGAGG-AAAGGGAg 3' MMP9}

Figure 1. Bioinformatics prediction of direct interactions between miR-204 and MMP9 using miRanda (www.microrna.org/microrna/home.do), TargetScan (www.targetscan.org), PiTa (genie.weizmann.ac.il/pubs/mir07/mir07_data. html), RNAhybrid (bibiserv.techfak.uni-bielefeld.de/rnahybrid) and PICTA (pictar.mdc-berlin.de/). miR, microRNA; MMP, matrix metalloproteinase; hsa, Homo sapiens.

Secretion of MMP9 protein into blood and saliva from pulpitis patients is enhanced in the presence of Hp infection in the stomach. ELISA was performed to examine the contents of MMP9 protein in the serum and saliva. The results indicated that the protein levels of MMP9 in serum and saliva from pediatric pulpitis patients with Hp infection in the stomach were significantly higher than those in pulpitis patients without Hp infection $(\mathrm{P}<0.05$; Fig. $4 \mathrm{~A}$ and $\mathrm{B})$. This result suggested that the secretion of MMP9 protein into blood and saliva is enhanced in the presence of Hp infection in the stomach.

miR-204 may have a regulatory role in the effect of $\mathrm{Hp}$ infection in the stomach on pulpitis in pediatric patients. To determine the expression of miR-204 in all samples, RT-qPCR was performed. The results indicated that the levels of miR-204 in pulp tissues, serum and saliva from pediatric patients with pulpitis and Hp infection in the stomach were significantly reduced compared with those in pediatric pulpitis patients without $\mathrm{Hp}$ infection $(\mathrm{P}<0.05$; Fig. 5A-C). This result indicated that miR-204 may have a regulatory role in the effect of Hp infection in the stomach on pulpitis in pediatric patients.

miR-204 regulates the expression of MMP9 by directly binding with the 3'-UTR of MMP9. To test whether miR-204 directly targets MMP9, a dual luciferase reporter assay was performed. The results indicated that transfection with agomiR-204 and pMIR-REPORT in the WT group resulted in significantly reduced fluorescence intensity compared with that in $\mathrm{NC}$ group $(\mathrm{P}<0.05)$, while the fluorescence intensity in mutant group was not significantly different from that in the negative control group ( $\mathrm{P}>0.05$; Fig. 6). This result suggested that miR-204 regulates the expression of MMP9 by directly binding with the 3'-UTR of MMP9.

\section{Discussion}

Hp was first isolated from gastric mucosa in patients with gastritis in 1983 (15). Later, Hp was detected in the majority of patients with active chronic gastritis, duodenal ulcer and gastric ulcer, and is considered as an important pathogenic factor for these diseases (16).

Sopata and Dancewicz (17) isolated MMP9 from neutrophile granulocytes and discovered that it degrades collagen. Furthermore, Murphy et al (18) revealed that MMP9 decomposes type IV gelatin and type V collagen. MMP9 is involved in various human diseases. Clinical studies have demonstrated that MMP9 has important roles in renal (19), breast (20) and 


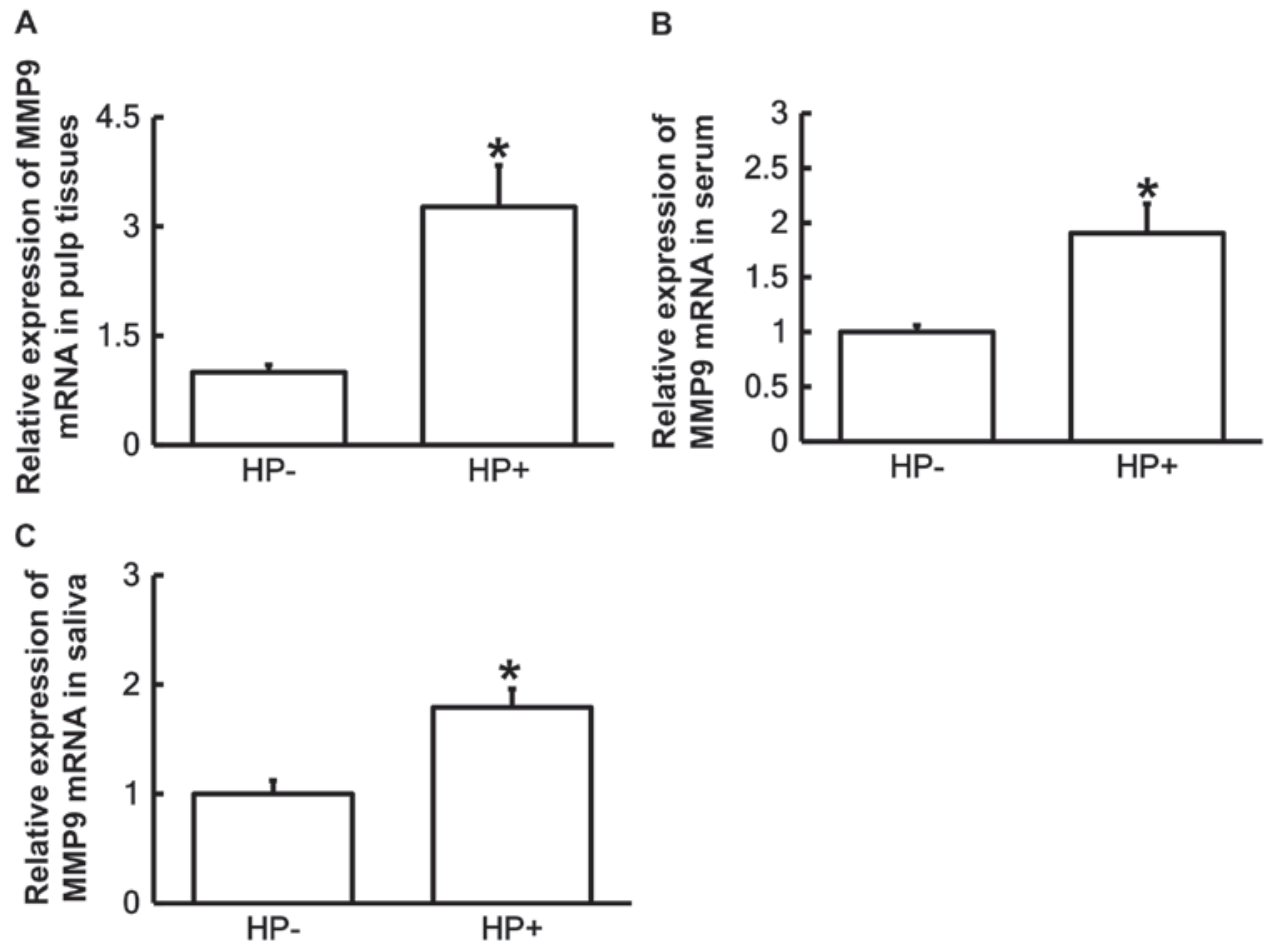

Figure 2. Expression of MMP9 mRNA in (A) pulp tissues, (B) blood and (C) saliva from children with pulpitis in the two groups. Reverse-transcription quantitative polymerase chain reaction was used to measure the expression of MMP9 mRNA. "P<0.05 compared with HP' group. Groups: HP+ $\mathrm{HP}^{+}$infection in the stomach; HP', no Hp infection in the stomach. MMP, matrix metalloproteinase; HP, Helicobacter pylori.

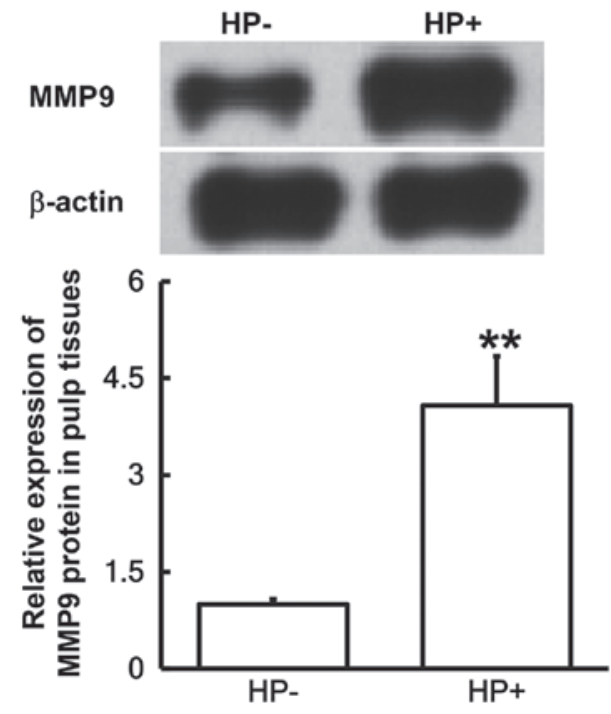

Figure 3. Expression of MMP9 protein in pulp tissues from children with pulpitis in the two groups. Western blot analysis was employed to measure the expression of MMP9 protein expression. ${ }^{* *} \mathrm{P}<0.01$ compared with $\mathrm{HP}$ group. Groups: $\mathrm{HP}^{+}, \mathrm{HP}$ infection in the stomach; $\mathrm{HP}^{-}$, no Hp infection in the stomach. MMP, matrix metalloproteinase; HP, Helicobacter pylori.

colorectal cancer $(21,22)$. Immunohistochemical study of MMP9 in the small mucosal type of gastric cancer indicated that invasion into the lamina propria epithelium is the first step in tumor invasion, and that MMP9 is aberrantly expressed in most mucosal lesions (23).

$\mathrm{Hp}$ is associated with gastric diseases, which may cause upregulation of MMP9. Previous studies on the association between MMPs and periodontal disease have confirmed the implication of MMPs $(24,25)$. Tjaderhane et al (26) proposed that acid production by bacteria activates MMP2 and MMP9 in the hosts, which then participate in the degradation of carious dentin. Furthermore, cytokines may also increase the expression of MMP2 and MMP9 in human dental pulp cells (27). The present study demonstrated that MMP9 levels in pulp tissues, serum and saliva from pediatric patients with pulpitis and Hp infection in the stomach were elevated, suggesting that $\mathrm{Hp}$ infection may further aggravate pulpitis by increasing MMP9 levels in pulp tissues, blood and saliva.

miRNAs are known to degrade their target mRNAs and inhibit their translation (28). In this way, miRNAs regulate the activity of multiple protein-coding genes by up- or downregulating the translation of their mRNA, to exert important roles in various diseases $(8,29)$. Under normal physiological conditions, the cleavage of MMP9 mRNA is associated with the downregulation of its protein expression. The bioinformatics study performed in the present study predicted that miR-204 as an upstream miRNA that regulates MMP9. A previous study reported that miR-204 affects the invasiveness of trophocytes by regulating MMP9 (12). It was also reported that miR-204 may be closely associated with inherited retinal dystrophy (30). An et al (31) discovered that downregulation of miR-204 induces the proliferation and invasion of human corneal epithelial cells. Regarding gastric disease, the role of miR-204 was mostly elucidated in gastric cancer. Chang et al (32) demonstrated that miR-204 levels in Hp-negative gastric cancer tissues were significantly higher than those in Hp-positive gastric cancer tissues. Zhang et al (33) reported that miR-204 inhibits the proliferation of gastric cancer cells by downregulating the expression of ubiquitin carboxyl-terminal hydrolase 47 and RAB22A. Zhou et al (23) demonstrated that expression of 

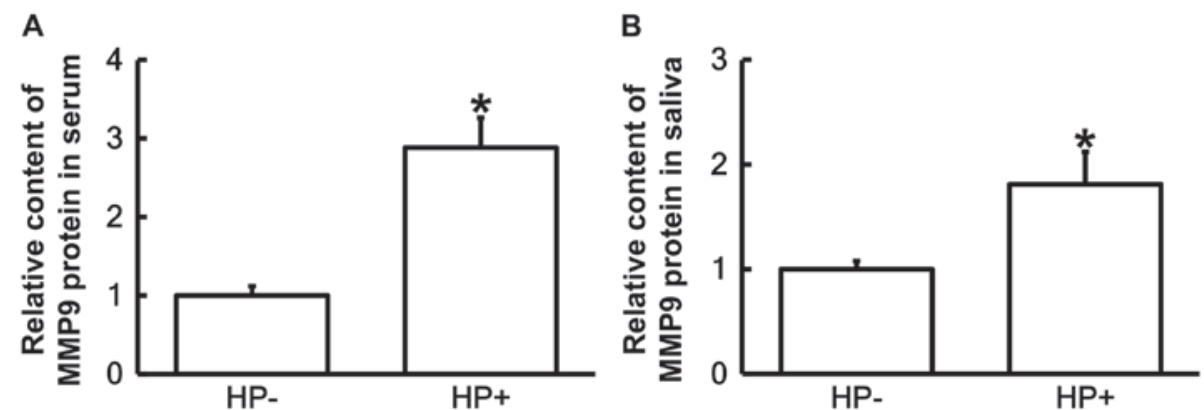

Figure 4. Contents of MMP9 protein in (A) blood and (B) saliva from children with pulpitis in the two groups. ELISA was performed to determine the content of MMP9. "P<0.05 compared with HP" group. Groups: $\mathrm{HP}^{+}$, HP infection in the stomach; HP', no Hp infection in the stomach. MMP, matrix metalloproteinase; HP, Helicobacter pylori.

A
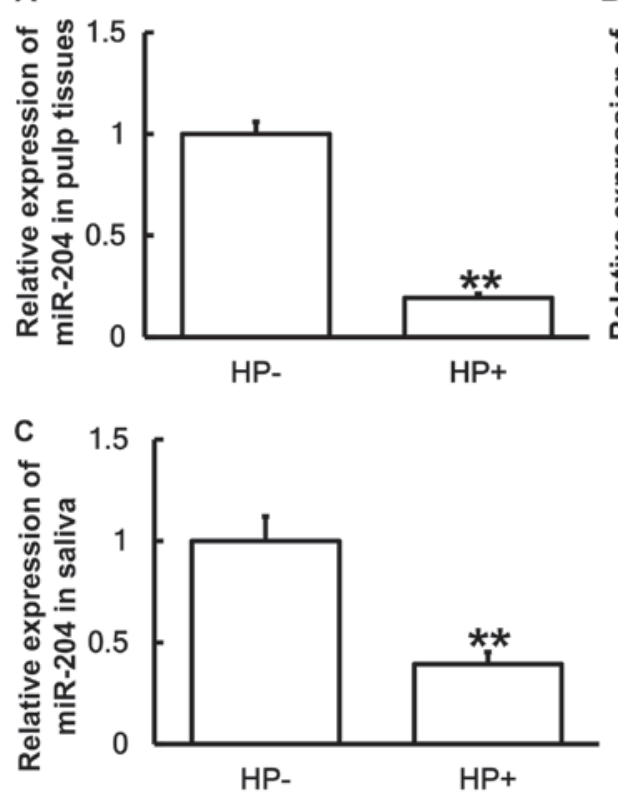

B

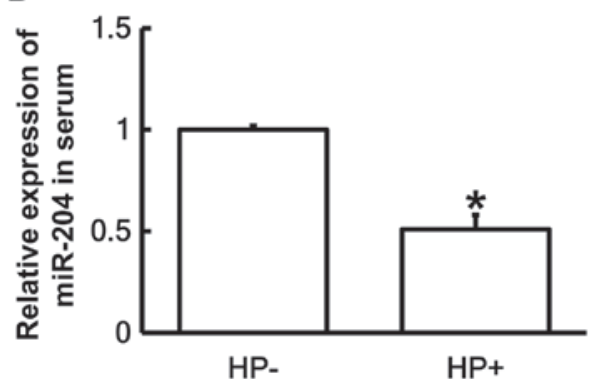

HP-

$\mathrm{HP}+$

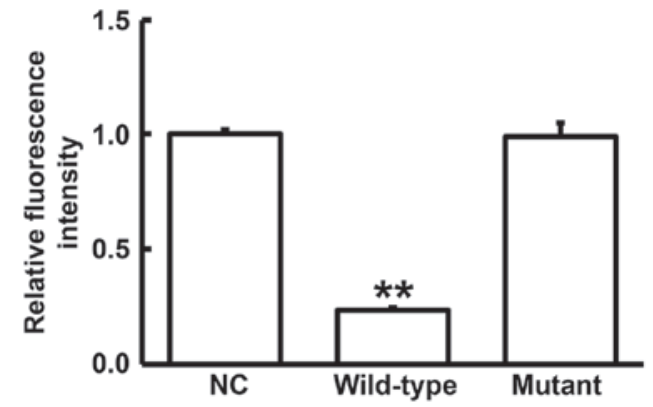

Figure 6. Fluorescence intensity of HEK293T cells transfected with wild-type or mutant sequences of the 3'-untranslated region of MMP9 and agomiR-204. A dual luciferase reporter assay was used to evaluate the interaction between miR-204 and MMP9. ${ }^{* *} \mathrm{P}<0.01$ compared with NC. NC, negative control; agomiR-204, microRNA-204 mimics; MMP, matrix metalloproteinase.

miR-204 in Hp-associated gastric carcinoma is significantly decreased, and that SRY-box 4 is a direct target of miR-204. A study by Zhang et al (34) indicated that miR-204 downregulates sirtuin 1-induced epithelial to mesenchymal transition, evasion of apoptosis and invasion of gastric cancer cells. The above studies demonstrated that miR-204 is involved in mucosal cell invasion. The present study revealed that expression of miR-204 was downregulated in pulp tissues from pediatric patients with pulpitis and Hp infection in the stomach compared with that in pediatric patients with pulpitis but without Hp infection, suggesting that MMP9 is likely to be directly regulated by miR-204. Downregulation of miR-204 expression weakened the cleavage of MMP9 mRNA and increased the transcription and translation of MMP9, finally aggravating the progression of pulpitis induced by MMP9. In addition, the decrease of miR-204 levels in blood and saliva suggested that this miRNA may be associated with oral infection by Hp. miR-204 is stable in serum and saliva, and may be a potential marker for the diagnosis of oral diseases in patients with Hp infection. Of note, sampling of saliva is non-invasive and simple, and analysis of certain molecular markers has high sensitivity and specificity, which therefore has diagnostic prospects for Hp infection in the stomach (35). In conclusion, the present study demonstrated 
that MMP9 expression in pulp tissues, blood and saliva from pediatric patients with pulpitis and Hp infection in the stomach was upregulated, while miR-204 expression was downregulated compared with those in pediatric pulpitis patients without $\mathrm{Hp}$ infection. miR-204 may affect inflammatory processes and other oral diseases in pediatric patients with pulpitis and $\mathrm{Hp}$ infection via MMP9, and may be a potential marker for the detection of Hp infection in pediatric patients with pulpitis.

\section{Acknowledgements}

Not applicable.

\section{Funding}

The current study was supported by a grant from the Jiangsu Provincial Preventive Medicine Research Foundation (grant no. Y2013003).

\section{Availability of data and materials}

The datasets used and/or analyzed during the current study are available from the corresponding author on reasonable request.

\section{Authors' contributions}

SZ and JX contributed to the design of the study. SZ performed the experiments. SZ and JX analyzed the data. SZ and JX interpreted results and prepared the manuscript. The final version of the manuscript has been read and approved by all authors.

\section{Ethics approval and consent to participate}

All procedures performed were approved by the Ethics Committee of Nanjing Medical University (Nanjing, China). Written informed consent was obtained from all patients or their families.

\section{Patient consent for publication}

Written informed consent for publication was obtained from all patients or their parents, guardians or next of kin.

\section{Competing interests}

The authors declare that they have no competing interests.

\section{References}

1. Akopyanz N, Bukanov NO, Westblom TU and Berg DE: PCR-based RFLP analysis of DNA sequence diversity in the gastric pathogen Helicobacter pylori. Nucleic Acids Res 20: 6221-6225, 1992.

2. Shiotani A, Cen P and Graham DY: Eradication of gastric cancer is now both possible and practical. Semin Cancer Biol 23: 492-501, 2013.

3. Villain P, Gonzalez P, Almonte M, Franceschi S, Dillner J, Anttila A, Park JY, De Vuyst H and Herrero R: European code against cancer 4th edition: Infections and cancer. Cancer Epidemiol 39 (Suppl 1): S120-S138, 2015.

4. Chen Y and Zhong LJ: The research progress of the correlation between Helicobacter pylori and periodontitis. Chin J Pract Stomatol 4: 752-754, 2011 (In Chinese).
5. Birkedal-Hansen H, Moore WG, Bodden MK, Windsor LJ, Birkedal-Hansen B, DeCarlo A and Engler JA: Matrix metalloproteinases: A review. Crit Rev Oral Biol Med 4: 197-250, 1993.

6. Wahlgren J, Salo T, Teronen O, Luoto H, Sorsa T and Tjäderhane L: Matrix metalloproteinase-8 (MMP-8) in pulpal and periapical inflammation and periapical root-canal exudates. Int Endod J 35: 897-904, 2002.

7. Gusman H, Santana RB and Zehnder M: Matrix metalloproteinase levels and gelatinolytic activity in clinically healthy and inflamed human dental pulps. Eur J Oral Sci 110: 353-357, 2002.

8. Chen K and Rajewsky N: The evolution of gene regulation by transcription factors and microRNAs. Nat Rev Genet 8: 93-103, 2007.

9. Greco S, Gorospe M and Martelli F: Noncoding RNA in age-related cardiovascular diseases. J Mol Cell Cardiol 83: 142-155, 2015.

10. Bienertova-Vasku J, Novak J and Vasku A: MicroRNAs in pulmonary arterial hypertension: Pathogenesis, diagnosis and treatment. J Am Soc Hypertens 9: 221-234, 2015.

11. Jamali Z, Asl Aminabadi N, Attaran R, Pournagiazar F, Ghertasi Oskouei S and Ahmadpour F: MicroRNAs as prognostic molecular signatures in human head and neck squamous cell carcinoma: A systematic review and meta-analysis. Oral Oncol 51: 321-331, 2015.

12. Yu Y, Wang L, Liu T and Guan H: MicroRNA-204 suppresses trophoblast-like cell invasion by targeting matrix metalloproteinase-9. Biochem Biophys Res Commun 463: 285-291, 2015.

13. Livak KJ and Schmittgen TD: Analysis of relative gene expression data using real-time quantitative PCR and the 2(-Delta Delta C(T)) method. Methods 25: 402-408, 2001.

14. Fu X, Zeng L, Liu Z, Ke X, Lei L and Li G: MicroRNA-206 regulates the secretion of inflammatory cytokines and MMP9 expression by targeting TIMP3 in Mycobacterium tuberculosis-infected THP-1 human macrophages. Biochem Biophys Res Commun 477: 167-173, 2016.

15. Warren JR and Marshall B: Unidentified curved bacilli on gastric epithelium in active chronic gastritis. Lancet 1: 1273-1275, 1983.

16. Marshall BJ and Warren JR: Unidentified curved bacilli in the stomach of patients with gastritis and peptic ulceration. Lancet 1: 1311-1315, 1984.

17. Sopata I and Dancewicz AM: Presence of a gelatin-specific proteinase and its latent form in human leucocytes. Biochim Biophys Acta 370: 510-523, 1974.

18. Murphy G, Cawston TE, Galloway WA, Barnes MJ, Bunning RA, Mercer E, Reynolds JJ and Burgeson RE: Metalloproteinases from rabbit bone culture medium degrade types IV and V collagens, laminin and fibronectin. Biochem J 199: 807-811, 1981.

19. Bhuvarahamurthy V, Kristiansen GO, Johannsen M, Loening SA, Schnorr D, Jung K and Staack A: In situ gene expression and localization of metalloproteinases MMP1, MMP2, MMP3, MMP9, and their inhibitors TIMP1 and TIMP2 in human renal cell carcinoma. Oncol Rep 15: 1379-1384, 2006.

20. Akkoc A, Inan S and Sonmez G: Matrix metalloproteinase (MMP-2 and MMP-9) and steroid receptor expressions in feline mammary tumors. Biotech Histochem 87: 312-319, 2012.

21. Cavdar Z, Canda AE, Terzi C, Sarioglu S, Fuzun M and Oktay G: Role of gelatinases (matrix metalloproteinases 2 and 9), vascular endothelial growth factor and endostatin on clinicopathological behaviour of rectal cancer. Colorectal Dis 13: 154-160, 2011.

22. Park KS, Kim SJ, Kim KH and Kim JC: Clinical characteristics of TIMP2, MMP2, and MMP9 gene polymorphisms in colorectal cancer. J Gastroenterol Hepatol 26: 391-397, 2011.

23. Zhou X, Li L, Su J and Zhang G: Decreased miR-204 in H. pylori-associated gastric cancer promotes cancer cell proliferation and invasion by targeting SOX4. PLoS One 9: e101457, 2014.

24. de Oliveira PA, de Pizzol-Junior JP, Longhini R, Sasso-Cerri E and Cerri PS: Cimetidine reduces interleukin-6, matrix metalloproteinases-1 and -9 immunoexpression in the gingival mucosa of rat molars with induced periodontal disease. J Periodontol 88: 100-111, 2017.

25. Liu N, Cao Y and Zhu G: Expression of matrix metalloproteinases-2, -9 and reversion-inducing cysteine-rich protein with Kazal motifs in gingiva in periodontal health and disease. Arch Oral Biol 75: 62-67, 2017.

26. Tjaderhane L, Larjava $H$, Sorsa $T$, Uitto VJ, Larmas $M$ and Salo T: The activation and function of host matrix metalloproteinases in dentin matrix breakdown in caries lesions. J Dent Res 77: 1622-1629, 1998. 
27. O'Boskey FJ Jr and Panagakos FS: Cytokines stimulate matrix metalloproteinase production by human pulp cells during long-term culture. J Endod 24: 7-10, 1998.

28. Liu K, Liu S, Zhang W, Jia B, Tan L, Jin Z and Liu Y: miR-494 promotes cell proliferation, migration and invasion and increased sorafenib resistance in hepatocellular carcinoma by targeting PTEN. Oncol Rep 34: 1003-1010, 2015.

29. Lewis BP, Burge CB and Bartel DP: Conserved seed pairing, often flanked by adenosines, indicates that thousands of human genes are microRNA targets. Cell 120: 15-20, 2005.

30. Conte I, Hadfield KD, Barbato S, Carrella S, Pizzo M, Bhat RS, Carissimo A, Karali M, Porter LF, Urquhart J, et al: MiR-204 is responsible for inherited retinal dystrophy associated with ocular coloboma. Proc Natl Acad Sci USA 112: E3236-E3245, 2015.

31. An J, Chen X, Chen W, Liang R, Reinach PS, Yan D and Tu L: MicroRNA expression profile and the Role of miR-204 in corneal wound healing. Invest Ophthalmol Vis Sci 56: 3673-3683, 2015.
32. Chang H, Kim N, Park JH, Nam RH, Choi YJ, Lee HS, Yoon H, Shin CM, Park YS, Kim JM and Lee DH: Different microRNA expression levels in gastric cancer depending on Helicobacter pylori infection. Gut Liver 9: 188-196, 2015.

33. Zhang B, Yin Y, Hu Y, Zhang J, Bian Z, Song M, Hua D and Huang Z: MicroRNA-204-5p inhibits gastric cancer cell proliferation by downregulating USP47 and RAB22A. Med Oncol 32: $331,2015$.

34. Zhang L, Wang X and Chen P: MiR-204 down regulates SIRT1 and reverts SIRT1-induced epithelial-mesenchymal transition, anoikis resistance and invasion in gastric cancer cells. BMC Cancer 13: 290, 2013.

35. Pickhardt PJ, Choi JR, Hwang I, Butler JA, Puckett ML, Hildebrandt HA, Wong RK, Nugent PA, Mysliwiec PA and Schindler WR: Computed tomographic virtual colonoscopy to screen for colorectal neoplasia in asymptomatic adults. N Engl J Med 349: 2191-2200, 2003. 